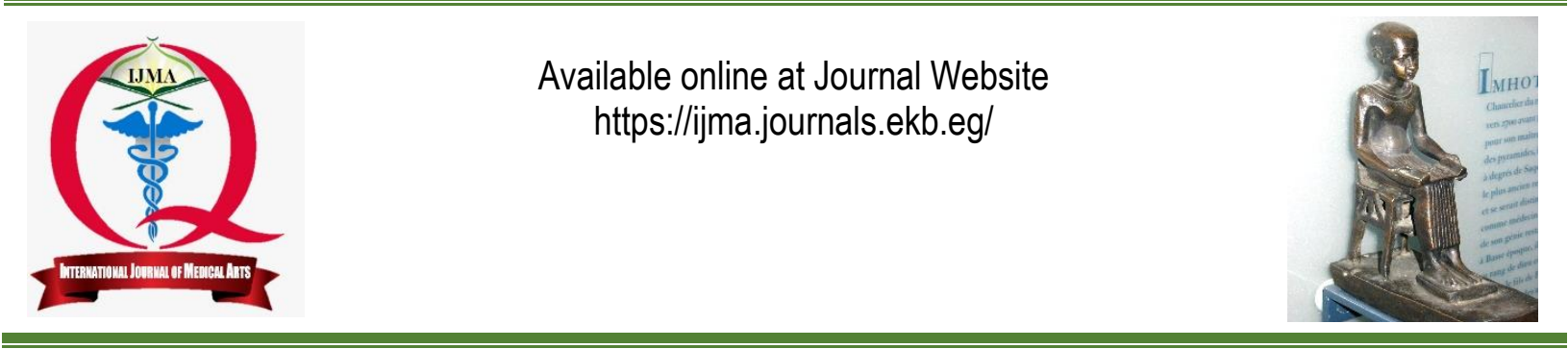

Original article

\title{
Efficacy of Ombitasvir/Paritaprevir/Ritonavir plus Ribavirin in Treatment of Chronic Hepatitis C Patients with End Stage Renal Disease on Regular Hemodialysis
}

\author{
Naglaa Atef El-Gendy ${ }^{a}$, Fathiya Mostafa EL-Raey ${ }^{b}$, Sherif Abdullah Nassib ${ }^{c}$, Noha Elsadany ${ }^{d}$ \\ Department of Hepatogastroenterology and Infectious Diseases, Faculty of Medicine for Girls, Al-Azhar University, Egypt [a] \\ Department of Hepatogastroenterology and Infectious Diseases, Damietta Faculty of Medicine, Al-Azhar University, Egypt [b] \\ Department of Internal Medicine, Faculty of Medicine for Girls, Al-Azhar University, Cairo, Egypt $[\mathrm{c}]$ \\ Department of Internal Medicine, Damietta Faculty of Medicine, Al-Azhar University, Egypt ${ }^{[\mathrm{d}]}$ \\ Corresponding author: Naglaa Atef El-Gendy \\ Email: drnaglaaelgendy@yahoo.com \\ Received at: December 30, 2019; Revised at: February 3, 2020; Accepted at: February 4, 2020; Available online at: February 4, 2020
} DOI: 10.21608/ijma.2020.21730.1068

\begin{abstract}
Background: Hepatitis $\mathrm{C}$ virus [HCV] infection is associated with more significant morbidity and mortality among dialysis patients than in healthy populations. The fixed-dose tablet [ombitasvir/ paritaprevir/ritonavir] in combination with ribavirin was effective and generally well tolerated in treatment of chronic HCV infected patients with end stage renal disease [ESRD] on hemodialysis. However, limited published data are known about the usefulness of this regimen for treatment of HCV patients with ESRD on hemodialysis.
\end{abstract}

Aim of the work: The aim of this study was to evaluate the safety and efficacy of treatment regimen of ombitasvir [OBV] $25 \mathrm{mg} /$ paritaprevir [PTV] $150 \mathrm{mg} /$ ritonavir [RTV] $100 \mathrm{mg}$ plus generic ribavirin [RBV] $200 \mathrm{mg}$ in Egyptian HCV-infected naive patients with ESRD on regular hemodialysis.

Patients and methods: A prospective cohort study involved 40 chronic HCV on regular hemodialysis patients, who were eligible for treatment with combined oral antiviral therapy.

Results: The results showed that thirty-five patients [35/40[87.5\%]] completed 12 weeks of HCV therapy; they had a virological response at end of therapy and sustained virological response. Anemia was the main observed side effect which lead to discontinuation of the treatment in five patients [12.2\%]. As these patients were not responding to anemia correction measures [blood transfusion, erythropoietin-stimulating agents, and modification of RBV dose].

Conclusion: OBV/PTVIRTV plus Ribavirin can be used in treatment of chronic HCV patients with ESRD on regular hemodialysis.

Keywords: Direct-acting antiviral drugs; End-stage renal diseases; Hepatitis C; Viral infection; Hemodialysis.

This is an open access article under the Creative Commons license [CC BY] [https://creativecommons.org/licenses/by/2.0/]

Please cite this article as El-Gendy NA, EL-Raey FM, Nassibi SA, Elsadany N. Efficacy of Ombitasvir/Paritaprevir/Ritonavir plus Ribavirin in Treatment of Chronic Hepatitis C Patients with End Stage Renal Disease on Regular Hemodialysis. IJMA 2020; 2[1]: 313-319. 


\section{INTRODUCTION}

Hepatitis $C$ virus infection prevalence among hemodialysis [HD] patients ranges from $5 \%$ to approximately $60 \%$ in different countries $[1,2]$.

Increased risk of morbidity and mortality in these patients favor the treatment of $\mathrm{HCV}$ infection[3,4].

Eradication of HCV help to reduce its prevalence and risk of nosocomial transmission in HD units [5, 6].

Early experience of combined therapy with pegylated interferon and ribavirin in these patients showed $40 \%$ sustained virological response with very poor tolerance, leading to withdrawal of this regimen in more than $1 / 3$ of patients[ ${ }^{[7]}$.

Although these limitations, this combination demonstrated the durability of virological response even post renal transplantation ${ }^{[8]}$.

Introducing of direct-acting antiviral drugs [DAAs] in treatment of $\mathrm{HCV}$ infection have led to a sustained virological response after 12 weeks of treatment [SVR12] in more than $90 \%-95 \%$ of the patients with improved tolerance. Fortunately, the NS5A inhibitor ombitasvir, the NS3/4A inhibitor paritaprevir and ritonavir are not excreted by the kidneys and do not need dose adjustment in severe CKD or in HD patients $[9,10]$.

Observational studies from Europe and the United States reported the use of ombitasvir/ paritaprevir/ ritonavir \pm dasabuvir \pm ribavirin in treatment of $\mathrm{HCV}$ infection in end stage renal disease [ESRD] [11,12].

An Egyptian study found that, ombitasvir/ paritaprevir/ritonavir in combination with ribavirin was generally well tolerated in treatment of $\mathrm{HCV}$ patients without cirrhosis or with compensated cirrhosis with 97 and $93 \%$ SVR12 respectively ${ }^{[13]}$.

\section{AIM OF THE WORK}

The aim of this study was to evaluate the safety and efficacy of a combination oral antiviral therapy [ombitasvir $25 \mathrm{mg} /$ paritaprevir $150 \mathrm{mg} /$ ritonavir $100 \mathrm{mg}$ ] plus generic ribavirin [200 mg] in treatment of chronic HCV-infected patients with end stage renal disease [ESRD] on regular hemodialysis.

\section{PATIENTS AND METHODS}

This is a prospective cohort study involved 40 Egyptian naive patients with chronic HCV infection and ESRD, attended to the Dialysis Units at AlZahraa University Hospitals and Damietta University Hospitals, Faculty of Medicine, Al-Azhar University, Cairo and Damietta respectively, during the period from March 2017 to September 2017.

All patients were enrolled in the Egyptian National Program for treatment of hepatitis C viral infection and according to the protocol designed by the Egyptian National Committee for Control of Viral Hepatitis launched in December 2016.

\section{Inclusion criteria:}

- Adults patients from both sexes;

- with chronic hepatitis $C$ viral infection proved by HCV antibodies and quantitative polymerase chain reaction of HCV RNA,

- had end stage renal disease proved by estimated glomerular filtration rate eGFR $<15 \mathrm{~mL} / \mathrm{min} / 1.73 \mathrm{~m}^{2}$ and imaging evidence, treatment naive,

- with fasting-blood-sugar [FBS] $\leq 140$ $\mathrm{mg} / \mathrm{dL}$, with base line levels of platelets count $\geq 150 \times 10^{3} / \mathrm{cc}$,

- Hemoglobin $[\mathrm{Hb}] \geq 10 \mathrm{~g} / \mathrm{dL}$, base line levels for serum total bilirubin was $\leq$ $1.2 \mathrm{mg} / \mathrm{dL}$, serum albumin was $\geq 3.5 \mathrm{~g} / \mathrm{dL}, \quad$ and international normalization ratio [INR] was $\leq 1.2$.

\section{Exclusion criteria:}

- Patients with low base line levels of platelets count $<150 \times 10^{3} / \mathrm{mm}^{3}, \mathrm{Hb}$ $<10 \mathrm{~g} / \mathrm{dL}$, serum total bilirubin more than $1.2 \mathrm{mg} / \mathrm{dL}$, INR more than 1.2 , serum albumin $<3.5 \mathrm{~g} / \mathrm{dL}$ and eGFR $>15 \mathrm{~mL} / \mathrm{min} / 1.73 \mathrm{~m}^{2}$.

- Patients with liver cirrhosis and or with Fib-4 score $>1.45$.

- Uncontrolled diabetic patients with glycated hemoglobin $[\mathrm{HbA} 1 \mathrm{C}]>9 \%$ and patients with associated uncontrolled co-morbidities [e.g. cardiac or neuropsychiatric disorders]. 
All patients were subjected to:

[A] - Careful history taking and thorough clinical examination.

[B]-Abdominal ultrasonography.

[C]- Laboratory investigations: Complete blood count [CBC], Liver function tests, Fasting blood sugar, $\mathrm{HbA} 1 \mathrm{c}$, Renal function test, Viral hepatitis markers; hepatitis $\mathrm{C}$ virus antibody [HCV-Ab] and hepatitis $B$ surface antigen [HBs-Ag] were detected using enzyme linked immunosorbent assay [ELISA] and Quantitative HCV-RNA was detected by realtime polymerase chain reaction [PCR] .

The value of eGFR was calculated by MDRD study equation as follow:

eGFR [estimated glomerular filtration rate] $=175 \times$ [Standardized serum Creatinine] $-1.154 \times$ [age]-0.203 $\times 0.742$ [if female] according to Stevens et al. [14].

Fib-4 score was calculated for each patient as the following:

Fib-4 score $=[$ Age $\times$ AST] $/$ [Platelets $\times$ [sqrt $[\mathrm{ALT}]]$. Where Fib4 score $<1.45=\mathrm{F} 0-\mathrm{F} 1$ and Fib4 score $>3.25=$ F3-F4 as illustrated by Martinez et al. [15].

Patients were on regular hemodialysis, for more than 3 months, 3 sessions /week, $4 \mathrm{~h} / \mathrm{session}$, bicarbonate-based dialysate. All of them received [Ombitasvir [OBV] $25 \mathrm{mg} /$ paritaprevir [PTV] $150 \mathrm{mg}$ /ritonavir [RTV] $100 \mathrm{mg}$ ] plus generic ribavirin [RBV] $200 \mathrm{mg}$ oral fixed daily dose for 12 weeks.

On the day of dialysis, ribavirin was given four hours before dialysis session while OBV/PTV/ RTV after dialysis session. The patients had completed HCV treatment for 12 weeks. Every 4 weeks of treatment, CBC, creatinine level, and hepatic function panel were done. Using PCR assay, quantitative HCV viral load testing was evaluated at both end of treatment [EOT] to detect the virological response to therapy [ETR] and 12 weeks after end of treatment to detect sustained virological response [SVR12].

Statistical Methods: The data was coded and analyzed with the program of Statistical Package for Social Science [IBM-SPSS], under Window version 22. Continuous parametric data were expressed as mean \pm standard deviation [SD], whereas nonparametric data were expressed as median.

Also, categorical data were expressed as frequencies [percentages]. Quantitative data with parametric distribution were done by using Analysis of variance [ANOVA].

Comparing groups were done by using Independent t-test and One-Way ANOVA test followed by post hoc test analysis using LSD.

The confidence interval was set to $95 \%$ and the margin of error accepted was set to $5 \%$. The $p$ value was considered non-significant [NS] at the level of $>0.05$, significant at the level of $<0.05$ and highly significant at the level of $<0.001$.

\section{RESULTS}

Forty chronic HCV patients [mean age was $53.85 \pm 11.6$ years] with ESRD started HCV oral combination therapy by ombitasvir/paritaprevir/ ritonavir plus generic ribavirin. Demographic data of the studied patients showed that, there 30 patients [75\%] were males and 10 patients [25\%] were females. Fifteen patients [37.5\%] were diabetics receiving insulin therapy and ten patients [25\%] were hypertensive. All patients had Fib4 score < 1.45 = F0-F1 [Tables 1 and 2].

Thirty-five out of 40 patients [35/40[87.5\%]] completed 12 weeks of therapy. All 35 patients who completed treatment achieved virological responses at end of treatment [EOT] and sustained virological response 12 weeks after EOT with undetectable HCVRNA. Five patients [12.5\%] patients had stopped treatment due to occurrence of marked reduction in hemoglobin level, which failed to respond to correction measures [transfusion of $1000 \mathrm{CC}$ packed RBCs, erythropoietin-stimulating agents 4000 IU SC weekly, and modification of RBV dose to be every other day] [Table [3].

Significant decreases were found in serum levels of ALT, AST and Hb during the course of treatment [week4, week8 and 12week] compared to their levels at the beginning $[p<0.05]$. There was significant increase in platelets count at the end of treatment compared to its levels at the beginning [p $<0.05$ ] [Table 4]. 
El-Gendy NA, et al.

Table [1]: Basic characteristics of the studied patients

\begin{tabular}{|l|c|c|}
\hline \multicolumn{2}{|c|}{ Variables } & Number of patients [40] \\
\hline Gender: & No & $\%$ \\
Males: & 30 & 75 \\
Females: & 10 & 25 \\
\hline Comorbidity & 15 & 37.5 \\
Diabetes: & 10 & 25 \\
Hypertension: & & \\
\hline Abdominal ultrasonography: & 28 & $70 \%$ \\
Liver: & 12 & $30 \%$ \\
Bright echo pattern: & 40 & $100 \%$ \\
Normal echo pattern: & 40 & $100 \%$ \\
Patent portal vein & 40 & $100 \%$ \\
Normal size spleen & & $100 \%$ \\
Absent Ascites: & 40 & $100 \%$ \\
Kidneys: & 40 & \\
Grade IV nephropathy & & \\
\hline Fib-4 Score < 1.45 & & \\
\hline
\end{tabular}

Table [2]: Basic laboratory data of the studied patients.

\begin{tabular}{|c|c|}
\hline \multicolumn{2}{|c|}{ Number of patients [40] } \\
\hline Variables & Mean $\pm S D$ \\
\hline HCVRNA[IU/L] & $1592896 \pm 574692$ \\
\hline ALT[IU/L] & $38 \pm 15.7$ \\
\hline AST[IU/L] & $32.6 \pm 14.9$ \\
\hline Albumin[g/L] & $4.3 \pm 0.3$ \\
\hline Total bilirubin[mg/dl] & $0.5 \pm 0.1$ \\
\hline INR & $1.1 \pm 0.1$ \\
\hline $\mathrm{Hb}[\mathrm{g} / \mathrm{L}]$ & $12.2 \pm 2.7$ \\
\hline WBCs $\left[\times 10^{3}\right] / \mathrm{cmm}$ & $6.4 \pm 2.7$ \\
\hline Platelets $\left[\times 10^{3}\right] / \mathrm{cmm}$ & $199 \pm 33$ \\
\hline Serum Creatinine[mg/dl] & $5.7 \pm 1.8$ \\
\hline Creatinine Clearance & $9.1 \pm 3.4$ \\
\hline
\end{tabular}

Variables expressed as Mean \pm SD. WBC: white blood cells, AST: aspartate aminotransferase, ALT: alanine aminotransferase, INR: international normalized ratio, HCV -RNA: hepatitis $\mathrm{C}$ virus -ribonucleic acid.

Table [3]: Characteristics of patients who discontinued the course of treatment.

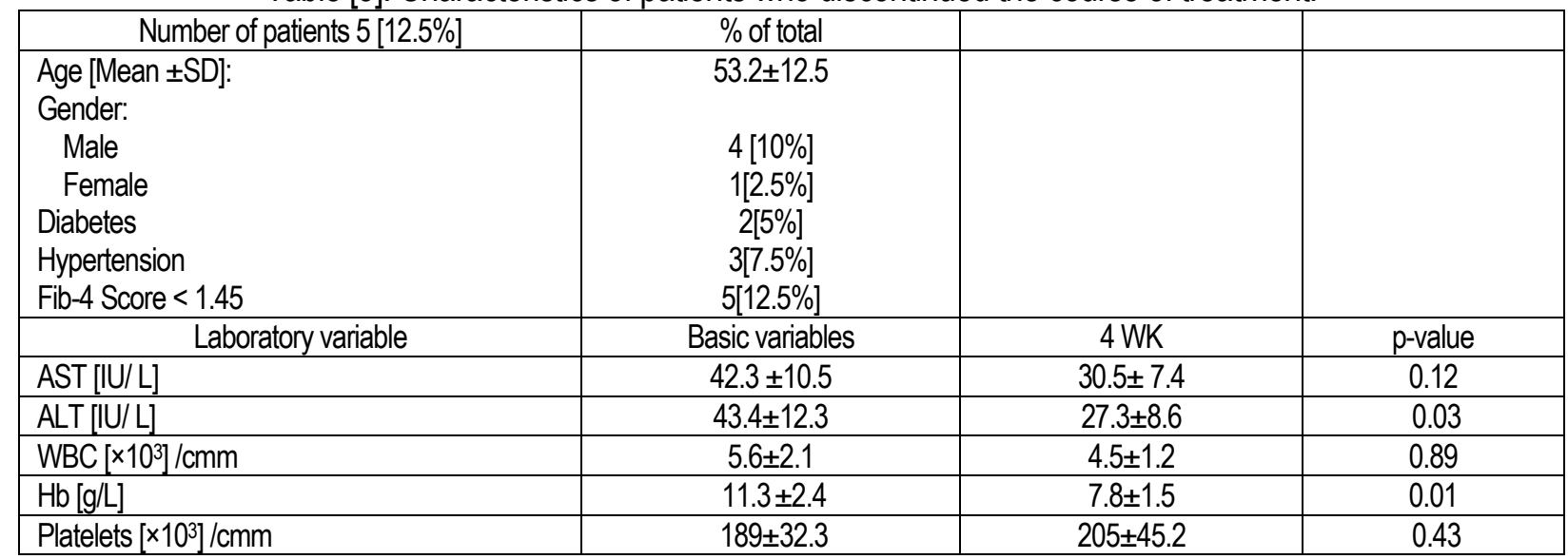

ALT: alanine aminotransferase, AST: aspartate aminotransferase; $\mathrm{Hb}$ : hemoglobin, WBCs: white blood cells. Means with different superscript letters are significantly different within the same row. Marked reduction in hemoglobin level despite significations improving in liver enzyme 
Table [4]: Follow up results of some laboratory parameters throughout the treatment course.

\begin{tabular}{|l|c|c|c|c|c|}
\hline \multicolumn{5}{|c|}{ Number of patients :35[87.5\%] } \\
\hline \multicolumn{1}{|c|}{ Variable } & Base line & 4th week & 8thweek & $12^{\text {th }}$ week & $\mathrm{p}$-value \\
\hline AST [IU/L] & $33 \pm 14.9^{\mathrm{a}}$ & $25.5 \pm 11.7^{\mathrm{b}}$ & $24.3 \pm 11.9^{\mathrm{b}}$ & $22.1 \pm 10.9^{\mathrm{b}}$ & $0.008[\mathrm{~S}]$ \\
\hline $\mathrm{ALT}[\mathrm{IU} / \mathrm{L}]$ & $34 \pm 15.7^{\mathrm{a}}$ & $23.1 \pm 10.8^{\mathrm{b}}$ & $21.4 \pm 9.7^{\mathrm{b}}$ & $20.3 \pm 8.4^{\mathrm{b}}$ & $0.001[\mathrm{~S}]$ \\
\hline WBC $\left[\times 10^{3}\right] / \mathrm{cmm}$ & $6.5 \pm 2.4$ & $6.4 \pm 2.7$ & $7.2 \pm 2.6$ & $7.1 \pm 1.4$ & $0.19[\mathrm{NS}]$ \\
\hline $\mathrm{HB}[\mathrm{g} / \mathrm{L}]$ & $12.1 \pm 1.6^{\mathrm{a}}$ & $10.2 \pm 2.3^{\mathrm{b}}$ & $9.8 \pm 2.1^{\mathrm{b}}$ & $10.1 \pm 1.5^{\mathrm{b}}$ & $0.001[\mathrm{~S}]$ \\
\hline Platelets $\left[\times 10^{3}\right] / \mathrm{cmm}$ & $196.1 \pm 33.8^{\mathrm{a}}$ & $209 \pm 61.7^{\mathrm{b}}$ & $219 \pm 67.4^{\mathrm{c}}$ & $224 \pm 69.2^{\mathrm{c}}$ & $0.03[\mathrm{~S}]$ \\
\hline Total bilirubin $[\mathrm{mg} / \mathrm{L}]$ & $0.5 \pm 0.1$ & $0.5 \pm 0.3$ & $0.5 \pm 0.2$ & $0.5 \pm 0.1$ & $1.00[\mathrm{NS}]$ \\
\hline
\end{tabular}

Variables expressed as Mean \pm SD. S: significant, NS: non-significant. The bars with the different letters are significantly different at $p<0.05$. ALT: alanine aminotransferase, AST: aspartate aminotransferase; WBCs: white blood cells. HB: hemoglobin, INR: international normalization ration,

\section{DISCUSSION}

Elimination of Hepatitis $\mathrm{C}$ virus [HCV] infection in patients with end-stage renal disease [ESRD] or requiring hemodialysis decreases liver disease progression and liver-related morbidity/mortality [16]. Also, reduces the risk of cardiovascular disease, diabetes and extra-hepatic cancers and improves their quality of life[17]. The access to new DAAs that mainly metabolized in the liver with minimal renal elimination as the ombitasvir,, and ritonavir-boosted paritaprevir [OBV/PTV/RTV] is available in a fixeddose combination pill[18]. This combination is requiring no dose adjustment in patients with renal impairment. However, for maximum virological response ribavirin [RBV] is added to this combination in patients with genotype $1 \mathrm{a}^{[19]}$.

Forty Egyptian naïve patients with ESRD were received combination of ombitasvir [25mg] I paritaprevir [150 mg]/ritonavir [100 mg], plus generic ribavirin [200 mg] for 12 weeks. There were $87.5 \%$ of the patients completed 12 weeks of HCV therapy. Such patients showed $100 \%$ a sustained virological response. In Japan, 10 chronic HCV patients genotype $1 \mathrm{~b}$ on regular hemodialysis received OBV/PTVIRTV combination therapy. Eight of them [80\%] completed 12 weeks therapy and achieved SVR12, while, two [20\%] patients discontinued the drugs because of its side effects [20]. More adherent to the therapy and less withdrawal rate were reported by Gómez et al. [11] and Pockros et al. [21]

Anemia was the main side effect occurred during the course of treatment in the current study. Impaired renal clearance increases the potential risk of ribavirin-induced hemolytic anemia[22]. Because of the distribution of RBV occurs mainly outside the plasma [primarily intracellular], since a very small amount of the drug in the body is available to be eliminated by dialysis [23]. Safety and efficacy of the RBV-free regimen ombitasvir/ paritaprevir/ ritonavir \pm dasabuvir in patients with ESRD [on hemodialysis] with HCV genotype 1a or 4 studied in RUBY-II clinical trial, which enrolled 18 treatment-naïve and non-cirrhotic adults patients. The overall SVR12 was 94\% [17/18]; one patient discontinued the study to undergo an elective renal transplantation[24].This combination well tolerated with no serious side effect. The authors concluded that RBV may not be necessary in some genotype 1a- or 4-infected patients with ESRD [on hemodialysis] [24].

Conclusion: OBV/PTV/RTV plus Ribavirin was an effective therapy of Egyptian naïve chronic HCV patients with end stage renal disease on regular hemodialysis.

Recommendation: Use OBV/PTV/RTV without Ribavirin in treatment of chronic HCV patients with end stage renal disease on regular hemodialysis to avoid resistant anemia and improve patients' adherence to treatment.

\section{Financial and Conflict of interest disclosure}

Authors declare that there was no conflict of interest.

\section{REFERENCES}

1.Di Napoli A, Pezzotti P, Di Lallo D, Petrosillo N, Trivelloni C, Di Giulio S, et al. Epidemiology of hepatitis $C$ virus among long-term dialysis patients: a 9-year study in an Italian region. Am J Kidney Dis. 2006;48[4]:629-37. [DOI: 10.1053/ j. ajkd.2006.07.004].

2.Alavian S-M, Kabir A, Ahmadi A, Lankarani K, Shahbabaie M, Ahmadzad-As M. Hepatitis C 
infection in hemodialysis patients in Iran: a systematic review. Hemodial Int. 2010;14[3]:25362. [Doi: 10.1111/j.1542-4758.2010. 00437.x].

3.Fabrizi F, Martin P, Dixit V, Bunnapradist S, Dulai G. Hepatitis $C$ virus antibody status and survival after renal transplantation: meta-analysis of observational studies. Am J Transplantation. 2005; 5[6]:1452-61. [DOI:10.1111/j. 1600-6143. 2005. 00864.x].

4.Fabrizi F, Takkouche B, Lunghi G, Dixit V, Messa $\mathbf{P}$, Martin P. The impact of hepatitis $\mathbf{C}$ virus infection on survival in dialysis patients: metaanalysis of observational studies. J Viral Hepatitis. 2007;14[10]:697-703. [DOI:10.1111/j.1365-2893. 2007. 00868.x].

5.Jadoul M, Fabrizi F. What are the management issues for hepatitis $C$ in dialysis patients? epidemiology and prevention of hepatitis $C$ virus transmission in the hemodialysis setting. Semin Dialysis. 2014; 27:449-51. [DOI: 10.1111/ sdi.12295].

6.Jadoul M, Horsmans Y. Towards eradication of hepatitis $\mathrm{C}$ virus from dialysis units. The Lancet. 2015; 386[10003]:1514-5. [DOI: 10.1016/S01406736(15)00381-5].

7.Gordon CE, Uhlig K, Lau J, Schmid CH, Levey AS, Wong JB. Interferon treatment in hemodialysis patients with chronic hepatitis $C$ virus infection: a systematic review of the literature and metaanalysis of treatment efficacy and harms. Am J Kidney Dis. 2008 Feb;51(2):263-77. [DOI: 10.1053/j.ajkd.2007.11.003].

8.Bhamidimarri KR, Martin P. Finally, safe and effective treatment options for hepatitis $C$ in hemodialysis patients. J Hepatol. 2016;65[1]:7-10. [DOI: 10.1016/j.jhep.2016.04.003].

9.Ferenci P, Bernstein D, Lalezari J, Cohen D, Luo Y, Cooper C, et al. ABT-450/r-ombitasvir and dasabuvir with or without ribavirin for HCV. New Engl J Med. 2014;370[21]:1983-92. [DOI: 10.1056/ NEJMoa1402338].

10.Kwo PY, Badshah MB. New hepatitis C virus therapies: drug classes and metabolism, drug interactions relevant in the transplant settings, drug options in decompensated cirrhosis, and drug options in end-stage renal disease. Curr Opin Organ Transplant. 2015;20[3]:235-41. [Doi: 10.1097/ MOT.0000000000000198].
11.Gómez R, Rincon D, Hernandez E, Ahumada A, Valderas MP, Devesa M, et al. Ombitasvir/ paritaprevir/ ritonavir plus dasabuvir are safety and eficacy for treating HCV GT1 and 4 infection in patients with severe renal impairment or end-stage renal disease: a multicenter experience. J Hepatol. 2016;64[2]: S813. [DOI: 10.1016/S0168-8278 (16) 01588-9].

12.Basu PP, Shah NJ, Aloysius M, Kavali L, Shehi E. Ombitasvir [ABT 267], ritanavir boost with dastasbuvir [ABT 333] and prataspravir [ABT 450] with or without ribavirin [RBV] in G1 special population in hemodialysis [HD] in chronic hepatitis $\mathrm{C}[\mathrm{HCV}]$ patients drop $\mathrm{C}$ trial. J Hepatol. 201664 [2]: S807-S8. [DOI: 10.1016/S01688278(16)01576-2].

13.Waked I, Shiha G, Qaqish RB, Esmat G, Yosry A, Hassany $\mathbf{M}$, et al. Ombitasvir, paritaprevir, and ritonavir plus ribavirin for chronic hepatitis $\mathrm{C}$ virus genotype 4 infection in Egyptian patients with or without compensated cirrhosis [AGATE-II]: a multicentre, phase 3, partly randomised openlabel trial. Lancet Gastroenterol Hepatol. 2016; 1[1]: 36-44. [DOI: 10.1016/S2468-1253(16)300024].

14. Stevens LA, Manzi J, Levey AS, Chen J, Deysher AE, Greene T, et al. Impact of creatinine calibration on performance of GFR estimating equations in a pooled individual patient database. Am J Kidney Dis. 2007 Jul;50[1]:21-35. [DOI: 10.1053/j.ajkd.2007.04.004]

15. Martinez SM, Fernández-Varo G, González $P$, Sampson E, Bruguera M, Navasa M, et al. Assessment of liver fibrosis before and after antiviral therapy by different serum marker panels in patients with chronic hepatitis C. Aliment Pharmacol Ther. 2011;33[1]:138-48. [DOI: 10.1111/j.1365-2036.2010.04500.x].

16. Omata M, Kanda T, Wei L, Yu ML, Chuang WL, Ibrahim A, et al. APASL consensus statements and recommendation on treatment of hepatitis $C$. Hepatol Int. 2016 Sep;10[5]:702-26. [DOI: 10.1007/s12072-016-9717-6].

17. European Association for the Study of the Liver [EASL]. EASL Recommendations on Treatment of Hepatitis C 2018; Clinical Practice Guidelines. J Hepatol. 2018 Aug;69[2]:461-511. [DOI: doi: 10.1016/j.jhep.2018.03.026]

18. Ramers CB, Trooskin SB. Hepatitis $C$ virus in the modern direct-acting antiviral era: where have all 
the special populations gone? Clin Liver Dis. 2018;12[5]:143-9. [DOI:10.1002/cld.786].

19. Polepally AR, Badri PS, Eckert D, Mensing S, Menon RM. Effects of mild and moderate renal impairment on ombitasvir, paritaprevir, ritonavir, dasabuvir, and ribavirin pharmacokinetics in patients with chronic HCV infection. Eur J Drug Metab Pharmacokinet. 2017;42[2]:333-9. [DOI: 10.1007/s13318-016-0341-6].

20. Morisawa N, Koshima $\mathrm{Y}$, Kuriyama $\mathrm{S}$, Matsuyama M, Hayashi N, Satoh Jl, et al. Effectiveness of a fixed combination formula of ombitasvir/paritaprevir/ritonavir for hepatitis $\mathrm{C}$ virus infection in patients on maintenance hemodialysis. Nephrology [Carlton]. 2017 Jul;22 [7]: 562-5. [DOI: 10.1111/nep.13011].

21. Pockros PJ, Reddy KR, Mantry PS, Cohen E, Bennett M, Sulkowski MS, et al. Efficacy of direct-acting antiviral combination for patients with hepatitis $C$ virus genotype 1 infection and severe renal impairment or end-stage renal disease. Gastroenterology. 2016;150[7]:1590-8. [DOl: 10.1053/j.gastro.2016.02.078].
22.Panel AlHG. Hepatitis C guidance: AASLD-IDSA recommendations for testing, managing, and treating adults infected with hepatitis $C$ virus. Hepatology. 2015;62[3]:932-54. [DOI: 10.1002/ hep.27950].

23. Brennan BJ, Wang $\mathrm{K}$, Blotner $\mathrm{S}$, Magnusson MO, Wilkins JJ, Martin P, et al. Safety, tolerability, and pharmacokinetics of ribavirin in hepatitis $C$ virus-infected patients with various degrees of renal impairment. Antimicrob Agents Chemother. 2013;57[12]:6097-105. [DOI: 10.1128/ AAC.00608-13].

24. Gane EJ, Sola R, Cohen E, Roberts SK, George J, Skoien R, et al. RUBY-II: efficacy and safety of a ribavirin-free ombitasvir/paritaprevir/ritonavir+/dasabuvir regimen in patients with severe renal impairment or end-stage renal disease and HCV genotypes 1a or 4 infection. Hepatology. 2016; 63 [1 SUPP]: 470A-1A. 